\title{
KINETIKA PENGERINGAN ASAM GELUGUR (Garcinia atroviridis) MENGGUNAKAN PENGERING SURYA TIPE KOLEKTOR TABUNG VAKUM DENGAN KONVEKSI PAKSA DAN ALAMI
}

\section{GARCINIA ATROVIRIDIS DRYING KINETICS USING EVACUATED TUBE SOLAR COLLECTOR DRYING WITH FORCED AND NATURAL CONVECTION}

\author{
Sari Farah Dina ${ }^{{ }^{*}}$, Siti Masriani Rambe ${ }^{1}$, Edwin Harianto Sipahutar ${ }^{1}$, Marisa Naufa ${ }^{1}$, \\ Zupri Adi Irhamsyah Tanjung ${ }^{2}$ \\ * main contributor and corresponding author \\ ${ }^{1}$ Balai Riset dan Standardisasi Industri Medan, Jl. Sisingamangaraja No. 24 Medan \\ ${ }^{2}$ PS Teknik Mesin - Fakultas Teknologi Industri, Institut Teknologi Medan, Jl. Gedung Arca no. 52 Medan \\ e-mail : sfdina1@kemenperin.go.id,
}

Diterima: 1 April 2019; Direvisi: 2019 - 25 Juli 2019; Disetujui: 30 Juli 2019

\begin{abstract}
Abstrak
Pengering surya tipe tabung vakum adalah alat yang berguna untuk mengeringkan hasil pertanian. Alat ini menggunakan dua metode pengeringan yaitu konveksi paksa dan konveksi alami. Pada penelitian ini bahan yang digunakan adalah asam gelugur (Garcinia atroviridis) yang merupakan salah satu komoditas pertanian di Indonesia. Penelitian ini bertujuan untuk mengeringkan asam gelugur dari kadar air 90,6\% menjadi $10-12 \%$ dengan variasi kecepatan aliran udara $0 \mathrm{~m} / \mathrm{s}, 3 \mathrm{~m} / \mathrm{s}, 3,5 \mathrm{~m} / \mathrm{s}$, dan $4 \mathrm{~m} / \mathrm{s}$ pada waktu pengeringan pagi dan siang hari, serta menentukan model kinetika yang sesuai pada pengeringan asam gelugur menggunakan pengering surya tipe tabung vakum. Berdasarkan hasil penelitian diperoleh pengeringan dengan kecepatan aliran udara $3 \mathrm{~m} / \mathrm{s}$ lebih baik di bandingkan dengan kecepatan $0 \mathrm{~m} / \mathrm{s}, 3,5 \mathrm{~m} / \mathrm{s}$ dan $4 \mathrm{~m} / \mathrm{s}$. Lama pengeringan berbanding lurus dengan intensitas radiasi matahari, namun berbanding terbalik dengan kecepatan aliran udara pada ruang pengering. Kelembaban yang terjadi didalan ruang pengering terdapat 2 fasa yaitu perpindahan panas dan perpindahan massa. Model kinetika pengeringan asam gelugur yang diperoleh yaitu model Wang \& Singh sesuai persamaan MR $=1-0,0034 t+0,000002 t^{2}$, dengan $R M S E=$ 0,0040-0,0074, dan MBE terendah = 0,0002-0,0006 dengan waktu 5,5 jam pada pengeringan siang hari.
\end{abstract}

Kata kunci: pengering surya, kolektor tabung vakum, konveksi paksa, konveksi alami, asam gelugur, model kinetika

\section{Abstract}

Evacuated tube solar dryers are useful tools for drying agricultural products. This tool uses two drying methods, namely forced convection and natural convection. In this study the raw material used were Garcinia atroviridis which is one of the agricultural commodities in Indonesia. This study aims to dry Garcinia atroviridis from water content of $90.6 \%$ to $10-12 \%$ with variations in air flow velocity $0 \mathrm{~m} / \mathrm{s}, 3 \mathrm{~m} / \mathrm{s}, 3.5 \mathrm{~m} / \mathrm{s}$, and $4 \mathrm{~m} / \mathrm{s}$ at the time of morning drying and during the day, and determine the kinetic model that is suitable for drying Garcinia atroviridis using a vacuum tube type solar dryer. Based on the results of the study obtained by drying with an air flow rate of $3 \mathrm{~m} / \mathrm{s}$ better compared with the speed of $0 \mathrm{~m} / \mathrm{s}, 3.5$ $\mathrm{m} / \mathrm{s}$ and $4 \mathrm{~m} / \mathrm{s}$. Quickly drying is directly proportional to the intensity of solar radiation, but inversely proportional to the speed airflow in the drying chamber. Moisture that occurs in the drying chamber there are 2 phases, namely heat transfer and mass transfer. The Garcinia atroviridis drying kinetic model obtained was Wang \& Singh model according to the equation $M R=1-0,0034 t+0,000002 t^{2}$, with $R M S E=0,0040-0,0074$, and the lowest $M B E=0,0002-0,0006$ with time 5.5 hours during daytime drying.

Keywords: solar dryer, vacuum tube collector, forced convection, natural convection, acid gland, kinetics model

\section{PENDAHULUAN}

Asam gelugur (Garcinia atroviridis) merupakan salah satu tanaman yang banyak di budidayakan di Indonesia, diantaranya adalah di propinsi Sumatera Utara. Selain popular sebagai konten masakan, asam gelugur juga dimanfaatkan untuk keperluan medis dan kosmetika [Mackeendkk, 2000; Elfita dkk, 2009]. Asam gelugur diketahui mengandung asam buah seperti asam sitrat, asam tartarat, asam malat dan asam askorbat yang memiliki akitivitas antioksidan. Meskipun belum ada hasil klinis mengenai manfaat asam gelugur, namun dari generasi ke generasi telah digunakan untuk mengobati sakit telinga, iritasi tenggorokan, batuk, ketombe dan gastralgia yang terkait dengan kehamilan. Asam gelugur juga telah dikaitkan seperti anti-inflamasi dan anti-jerawat. [Tisdale dkk, 2003].

Sebagai saah satu komoditi ekspor , asam gelugur dituntut harus memiliki beberapa persyaratan tertentu. Untuk itu pengolahan pasca panen menjadi parameter penting untuk mengawal kualitas yang diinginkan.

Asam gelugur perlu segera diolah menjadi bentuk akhir yang stabil agar aman 
untuk disimpan dalam jangka waktu tertentu. Selain mengontrol kadar air, kriteria mutu asam potong meliputi aspek fisik, cita rasa dan kebersihan serta aspek keseragaman dan konsistensi juga juga menjadi persyaratan yang harus dikendalikan Rajago[al dkk, 2014).

Pengeringan merupakan salah satu cara efektif untuk mengawetkan asam gelugur agar dapat disimpan dalam jangka waktu tertentu. Di Indonesia, asam gelugur umumnya dikeringkan dengan cara penjemuran langsung selama $3-5$ hari (tergantung cuaca). Beberapa kendala yang dihadapi petani terkait estetika warna asam gelugur yang dikeringkan adalah efek browning.

Beberapa metode pengeringan buatan telah dilakukan untuk mengantisipasi kelemahan dari metode konvensional ini.

Salah satu jenis pengering surya yang dapat dikembangkan adalah jenis kolektor tabung vakum (KTV). Pengeringan wortel, apel dan apricot menggunakan KTV telah dilakukan untuk mendapatkan kajian analisa kinerja termodinamika (Lamnatoudkk, 2012). Pengeringan cabai menggunakan pengering surya tipe kolektor KTV telah mampu mempersingkat waktu pengeringan dibandingkan dengan penjemuran langsung (Sundari dkk, 2013). Pengering dengan tipe ini diketahui lebih efisien karena dapat menghasilkan suhu udara pengering lebih tinggi dibanding suhu udara hasil pemanasan dari kolektor pelat datar [Venkatesan dkk, 2014].

Dasin D.Y et al .,2015) telah melakukan pengeringan merica, ikan, tomat dan talas menggunakan pengering KTV dan diperoleh waktu pengeringan lebih singkat dibanding penjemuran langsung.

Rancang bangun pengering kolektor tabung vakum untuk mengeringkan hasil pertanian telah dilakukan [Dina dkk, 2018]. Pengering ini dioperasikan secara konveksi paksa dengan suhu ruang pengering $35-78$ ${ }^{\circ} \mathrm{C}$ [Dina dkk, 2018].
Penerapan dan pemantauan proses pengeringan yang baik sangat diperlukan untuk menjaga kualitas hasil pengeringan. Untuk itu, formasalisasi fenomena seringkali digunakan untuk menjelaskan hubungan penurunan kadar air dan waktu pengeringan dengan cara membangun model persamaan matematis (Verdier N. dkk, 2015).

Pada penelitian ini akan mongeringkan asam gelugur dari kadar air $90,6 \%$ menjadi $10-12 \%$ dengan metode konveksi paksa dan alami serta melihat tingkat laju pengeringan, profil kondisi pengeringan tenaga surya hasil pertanian dan model kinetika.

\section{METODE}

\section{Bahan}

Buah dari marga tumbuh-tumbuhan atau suku Clusiaceae Garcinia jenis asam gelugur (Garcinia atroviridis) yang digunakan berasal dari kabupaten Deli Serdang provinsi Sumatera Utara, yang diiris-iris dengan tebal $\pm 1 \mathrm{~mm}$.

\section{Prosedur Percobaan}

Pengeringan buah asam gelugur yang dilakukan pada tanggal $20 \mathrm{~s} / \mathrm{d} 30$ Agustus 2018 dengan memanfaatkan energy termal matahari dari jam 09.00-17.30 WIB. Sebelum asam gelugur yang akan dikeringkan di letakkan didalam ruang pengering, blower dihidupkan untuk mengalirkan udara dari kolektor tabung vakum ke manifold lalu didistribusikan keruang pengering agar udara di dalam ruang pengering stabil. Pada metode konveksi paksa van pada ruang pengering dihidupkan untuk membuang uap air yang ada di dalam ruang pengering ke lingkungan.

Pengeringan dilakukan pada pagi hari dan siang hari. Pengeringan dihentikan bila kadar air sampel asam gelugur sudah sekitar $10-12 \%$. 


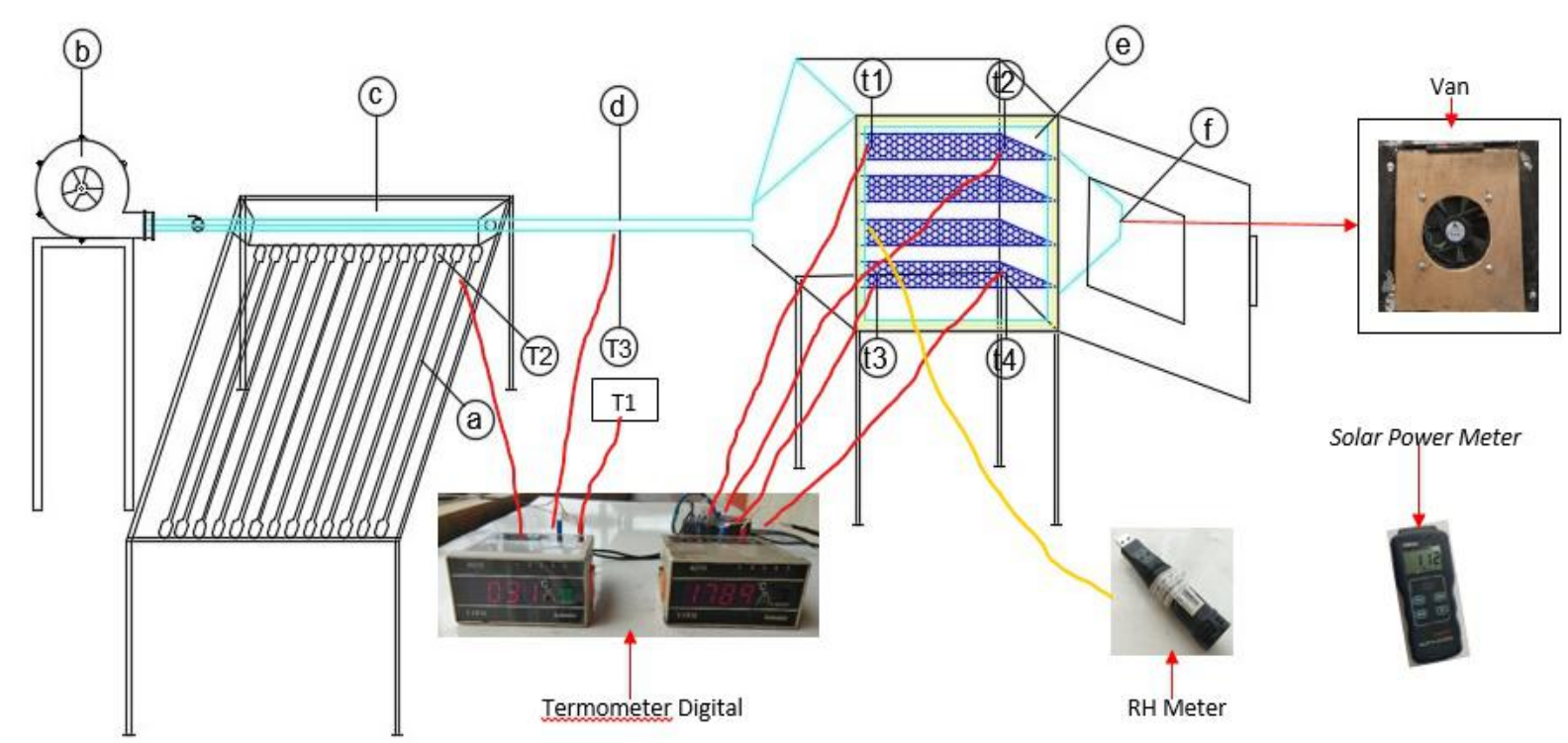

Gambar 1. Alat Pengering Tenaga Surya

Keterangan: $\mathrm{T1}: \mathrm{Temperatur}$ a.Kolektor lingkungan

tabung vakum T2 : Temperatur kolektor

b.Blower $\quad$ T3 : Temperatur manifold

c.Manifold $\quad \mathrm{T} 4=\mathrm{t} 1$ : Titik 1 pada oven

d.PipaTransmisi t2 : Titik 2 pada oven

e.Ruang t3 : Titik 3 pada oven

pengering t4 :Titik 4 pada oven

f.Van

Potensi energi surya diperoleh melalui pengukuran keadaan cuaca yang meliputi : intensitas radiasi (solar power meter), temperatur udara (ambient measurement apparatur) dan kelembaban (Tand $\mathrm{RH}$ smart sensor).

\section{Dasar Perhitungan}

a. Periode Laju Pengeringan

Untuk mengetahui kualitas pengeringan yang bagus, ada beberapa parameter yang harus dikontrol selama proses pengeringan, yaitu kecepatan aliran udara, temperatur udara pengering dan kelembaban relatif udara (Henderson \& Perry, 2009).

$$
\mathrm{m}_{\mathrm{d}}=\frac{M i-M f}{t} .
$$

Keterangan :

$\mathrm{m}_{\mathrm{i}} \quad=$ berat produk mula-mula (gram)

$\mathrm{m}_{\mathrm{f}} \quad=$ berat akhir produk (kering) (gram)

$\mathrm{t}=$ waktu pengeringan (menit)

b. Penentuan Kelembaban Rasio (MR)

Semua parameter ini dinyatakan dalam basis kering. (Kavak, A.E., 2010).

$\mathrm{MR}=\frac{M t-M e}{M i-M t}$

Keterangan :

MR = Rasio Kadar Air (\%)

$\mathrm{M}_{\mathrm{t}} \quad=$ Kadar Air Pada Waktu Aktual (\%)

$\mathrm{M}_{\mathrm{i}} \quad=$ Kadar Air Awal (\%)

$\mathrm{Me}_{\mathrm{e}} \quad$ = Kadar Air Setimbang (\%)

c. Hilangnya Kadar Air Jumlah air yang diuapkan menggunakan persamaan sebagai berikut: (Kavak, A.E., 2010).

$\mathrm{ML}=\left(\mathrm{M}_{\mathrm{i}}-\mathrm{M}_{\mathrm{f}}\right)$

Keterangan :

$\mathrm{M}_{\mathrm{i}} \quad=$ Massa bahan sebelum pengeringan (gram)

$\mathrm{M}_{\mathrm{f}} \quad=$ Massa bahan setelah pengeringan (gram)

d. Pemodelan Matematika Pengeringan 
Kinetika Asam Gelugur

Parameter statistic dihitung menggunakan persamaan berikut (Clement et al.,, 2009) :

$R M S E=\left[\frac{1}{N} \sum_{i-1}^{N}\left(M R E_{\text {exp }, i}-M R E_{\text {pred }, i}\right)^{2}\right]^{1 / 2} \ldots \ldots$
$M B E=\frac{1}{N} \sum_{i-1}^{N}\left(M R_{\text {pred }, i}-M R_{\text {exp }, i}\right)$

Ketereangan :

$M R_{\text {exp, I }}=$ eksperimental diamati rasio.

$M R_{\text {pred }, i}=$ kelembaban diperkirakan rasio.

$\mathrm{N} \quad=$ jumlah pengamatan

$\mathrm{N} \quad=$ jumlah konstanta.

(4)

Tabel 1. Model matematis yang dipilih untuk pencocokan kurva pengeringan pada penelitian

\begin{tabular}{ccc}
\hline No & Persamaan Model & Nama \\
\hline 1 & $M R=\exp (-k t)$ & Newton \\
\hline 2 & $M R=a \exp (-k t)$ & Henderson \& Pabis \\
\hline 3 & $M R=\exp \left(-k t^{n}\right)$ & Page \\
\hline 4 & $M R=1+a t+b t^{2}$ & Wang and Singh \\
\hline
\end{tabular}

Sumber: Clement et al., 2009

\section{HASIL DAN PEMBAHASAN}

\section{Profil Laju Pengeringan Terhadap Intensitas Radiasi Matahari}

Proses pengeringan asam gelugur pada penelitian ini dilakukan pada pagi dan siang hari. Dari pengukuran intensitas radiasi matahari, temperatur kolektor, manifold, dan ruang pengering diperoleh sebuah grafik profil laju pengeringan. Pengujian pada pagi hari dilakukan pada tanggal 20, 23, 25, dan 29 Agustus 2018 dimulai pukul 09.00 WIB sampai kadar air asam gelugur menjadi10-12\%. Hasil pengujian secara grafik dapat di lihat pada Gambar 2.

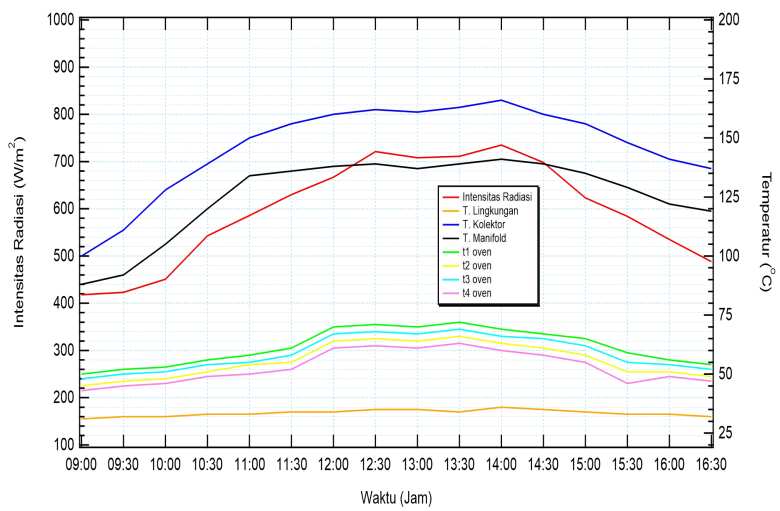

(a. Pengeringan 20 Agustus 2018)

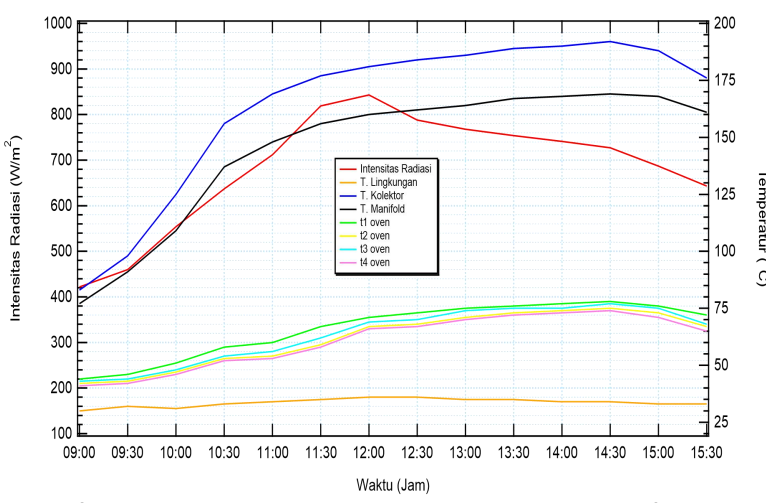

(b. Pengeringan 23 Agustus 2018)

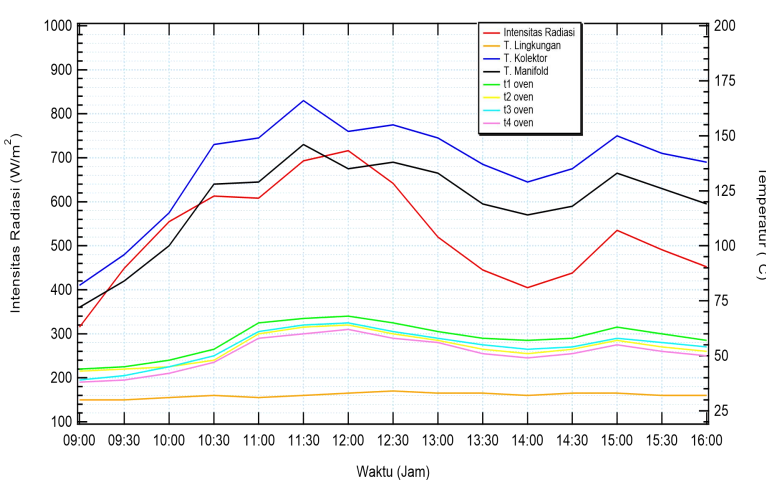

(c.Pengeringan 25 Agustus 2018) 


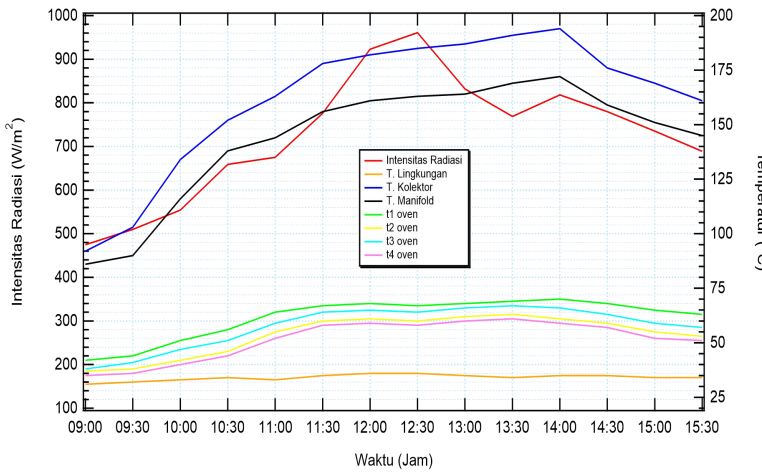

(d. Pengeringan 29 Agustus 2018)

Gambar 2. Grafik Profil Laju PengeringanTerhadap Intensitas Radiasi matahari Pada Percobaan Pagi Hari

Proses pengeringan pada pagi hari dipengaruhi oleh nilai intensitas radiasi yang diterima oleh kolektor surya sehingga menentukan kenaikan emperatur media pengering yang memasuki ruang pengering. Pada tanggal 23 Agustus 2018 merupakan pengeringan yang tercepat dengan waktu 6,5 jam dengan radiasi matahari tertinggi yaitu $843 \mathrm{~W} / \mathrm{m}^{2}$. Faktor intensitas radiasi matahari sangat berpengaruh terhadap kinerja mesin pengering surya seperti yang dapat dilihat pada Gambar 2.

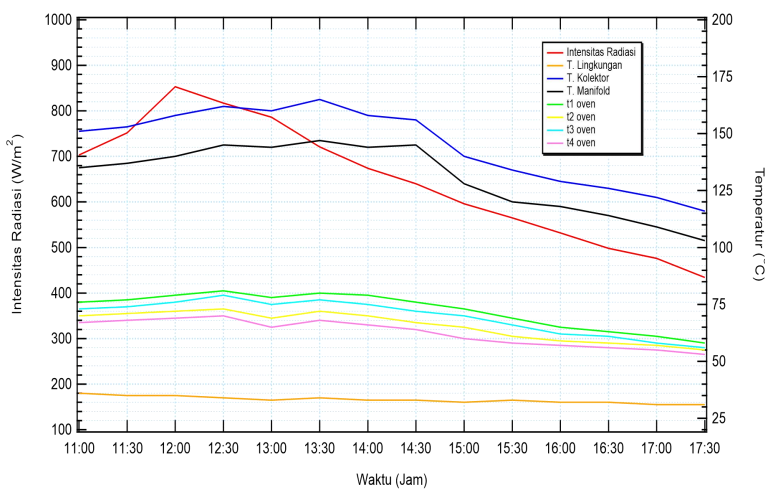

(a.Pengeringan 21 Agustus 2018)

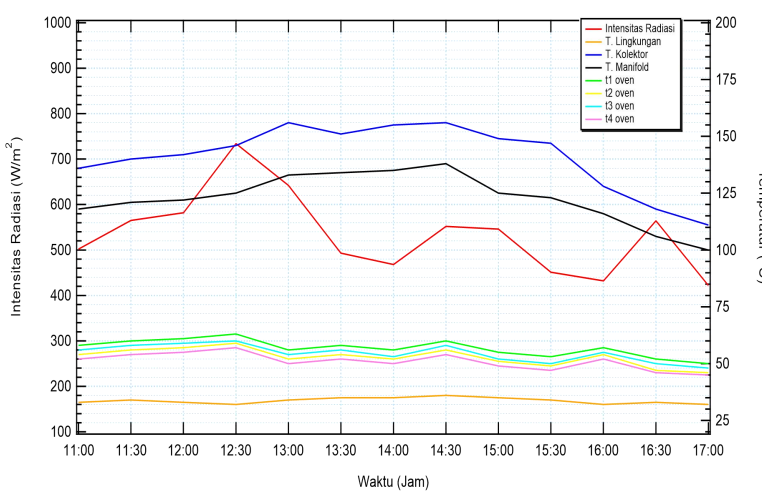

(b.Pengeringan 24 Agustus 2018)

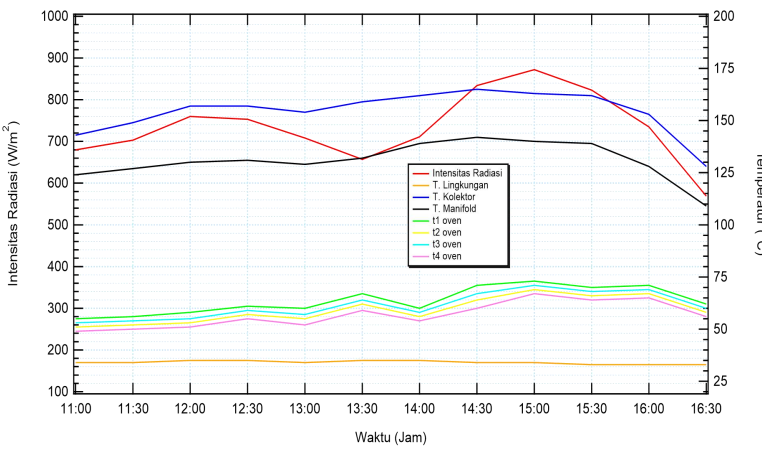

(c. Pengeringan 25 Agustus 2018)

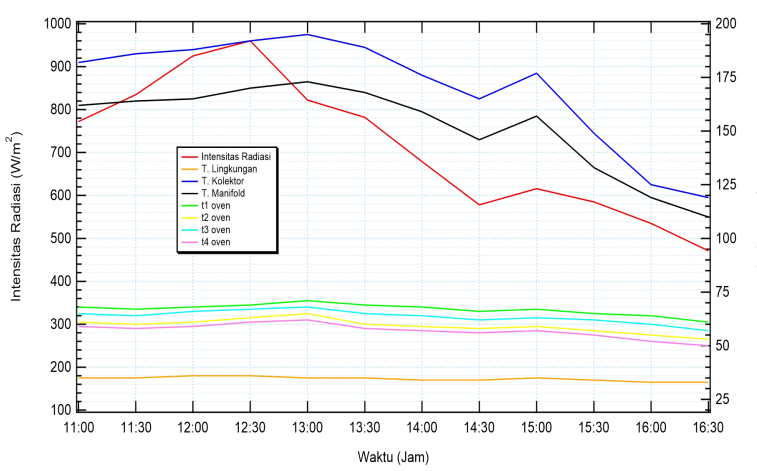

(d) Pengeringan 30 agustus 2018)

Gambar 3. Grafik Profil Laju Pengeringan Terhadap Intensitas Radiasi matahari Pada Percobaan Pagi Hari

Panas dikolektor sangat bergantung pada intensitas radiasi matahari yang diterima pada setiap tabung kolektor, semakin besar radiasi matahari maka semakin besar pula suhu dikolektor dan semakin besar juga temperatur di ruang pengering.

Pengujian pada siang hari dilakukan pada tanggal 21, 24, 28 dan 30 Agustus 2018 dimulai pukul 11.00 WIB sampai kadar air asam gelugur menjadi10-12\%. Hasil pengujian secara grafik dapat di lihat pada Gambar 3.

Proses pengeringan pada siang hari dipengaruhi oleh nilai intensitas radiasi yang diterima oleh kolektor surya sehingga menentukan kenaikan temperatur media pengering yang memasuki ruang pengering. Pada tanggal 30 Agustus 2018 merupakan a) pengeringan yang tercepat dengan waktu 5,5 jam dengan radiasi matahari tertinggi yaitu $843 \mathrm{~W} / \mathrm{m}^{2}$. Faktor intensitas radiasi matahari sangat berpengaruh terhadap kinerja mesin pengering surya seperti yang dapat dilihat pada Gambar 3. Panas dikolektor sangat bergantung pada intensitas radiasi matahari yang diterima pada setiap tabung kolektor, semakin besar radiasi 
matahari maka semakin besar pula suhu dikolektor dan semakin besar juga temperatur di ruang pengering dan grafik diatas juga dipengaruhi oleh waktu mulainya pengujian karena semakin siang dimulainya pengujian maka suhu di dalam ruang pengering semakin naik dikarenakan intensitas matahari yang memanaskan sisi luar ruang pengering.

\section{Profil Laju Pengeringan Terhadap Kondisi Pengeringan}

Pentapan profl ini dilakukan dengan dasar asumsi bahwa distribusi suhu dan kelembaban adalah seragam, pengeringan berlangsung Dari hasil pengukuran kelembaban udara didalam ruang pengering diperoleh data humiditas relative, humiditas mutlak, dan temperatur. Data kelembaban udara yang telah dirata-ratakan per 30 menit pada tanggal $20 \mathrm{~s} / \mathrm{d} 30$ Agustus 2018 disajikan pada Gambar 4 dan Gambar 5.

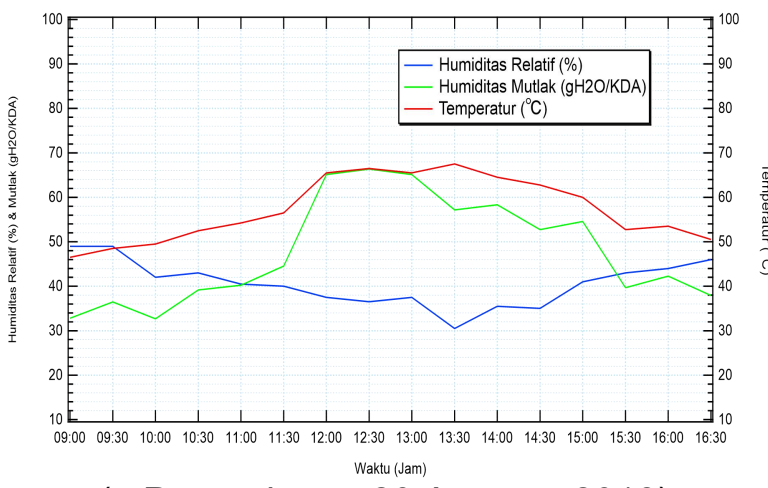

(a.Pengeringan 20 Agustus 2018)

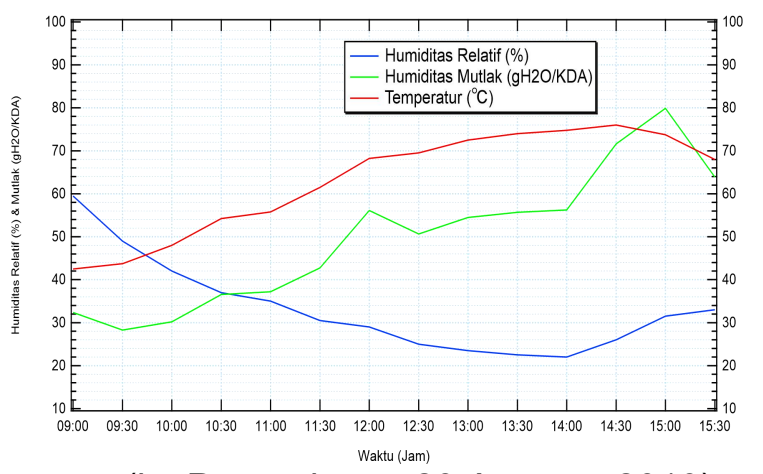

(b. Pengeringan 23 Agustus 2019)

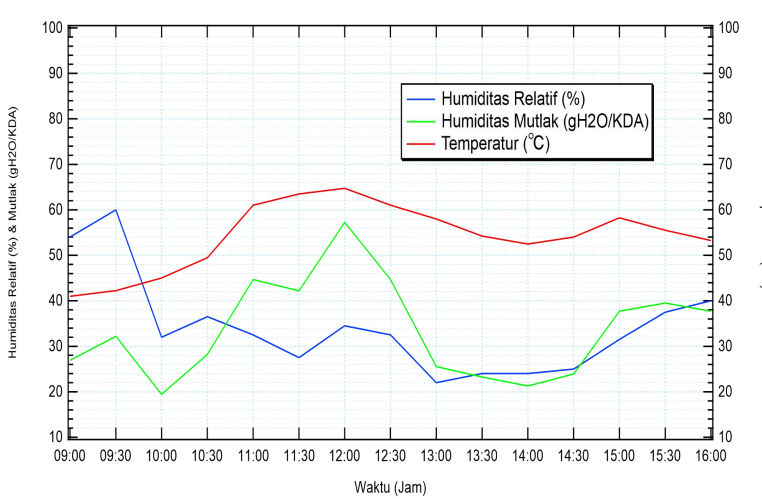

(c. Pengeringan 25 Agustus 2018)

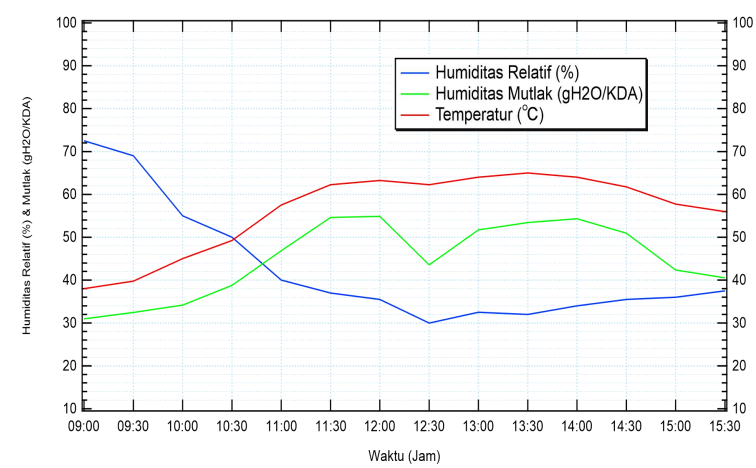

(d. Penegringan 29 agustus 2018)

Gambar 4. Grafik Profil Laju Pengeringan Terhadap Kondisi Pengeringan Pada Percobaan Pagi Hari

Pada daerah yang beriklim tropis seperti Indonesia, humiditas udara umumnya sangat tinggi sehingga proses pengeringan pada suhu dibawah $100^{\circ} \mathrm{C}$ mempunyai drying rate yang rendah. Hal ini memakan waktu lama dan bahkan dianggap tidak efisien. Hasil pengukuran menunjukkan bahwa pada pukul 15.00 WIB proses pengeringan asam gelugur dapat menghilangkan kadar air yang terkandung pada asam gelugur dengan paling cepat yaitu mencapai $79,89 \%$. \%. Humiditas relatif berbanding terbalik dengan humiditas mutlak. Semakin menurun humiditas relatif dalam ruang pengering, maka semakin menigkat massa dari uap air pada asam gelugur dan sebaliknya. Kelembaban udara yang terjadi didalam ruang pengering didapatkan dengan meletakkan alat ukur kelembaban RH-T yang telah diatur dengan komputer lalu alat tersebut diletakkan didalam ruang pengering. 


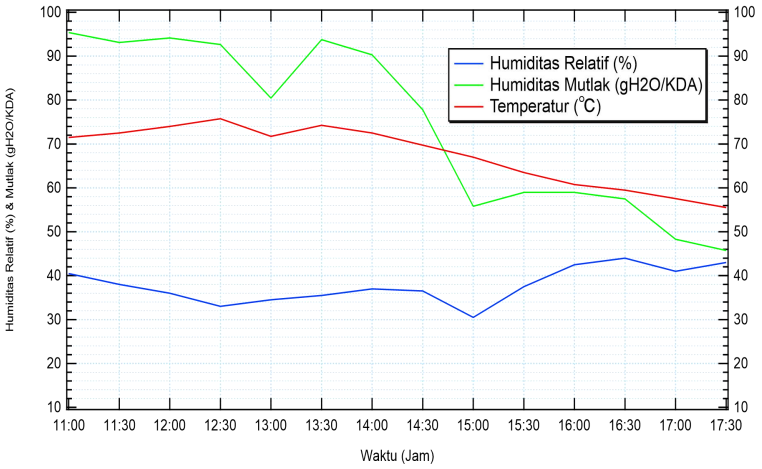

(a) Pengeringan 21 Agustus 2018)

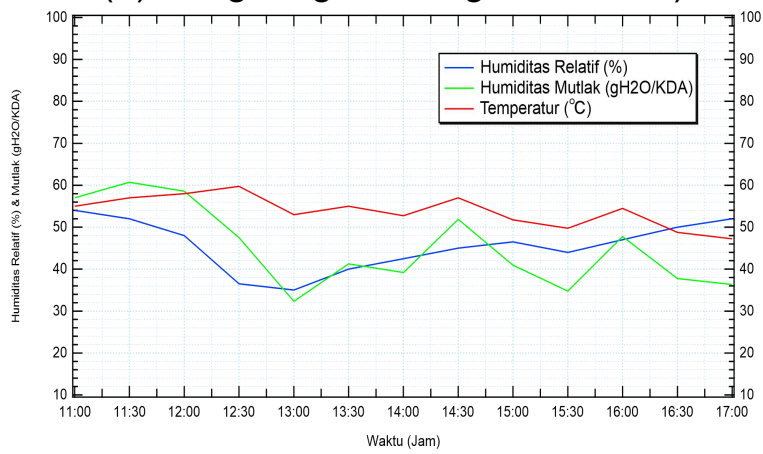

(b) Pengeringan 24 Agustus 2018)

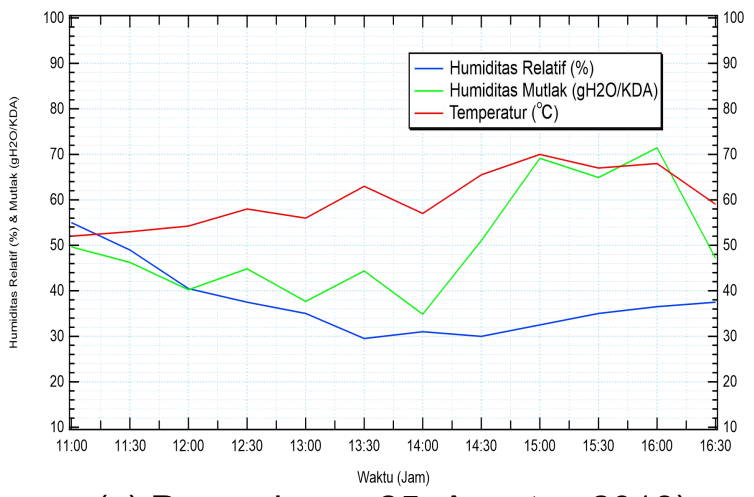

(c) Pengeringan 25 Agustus 2018)

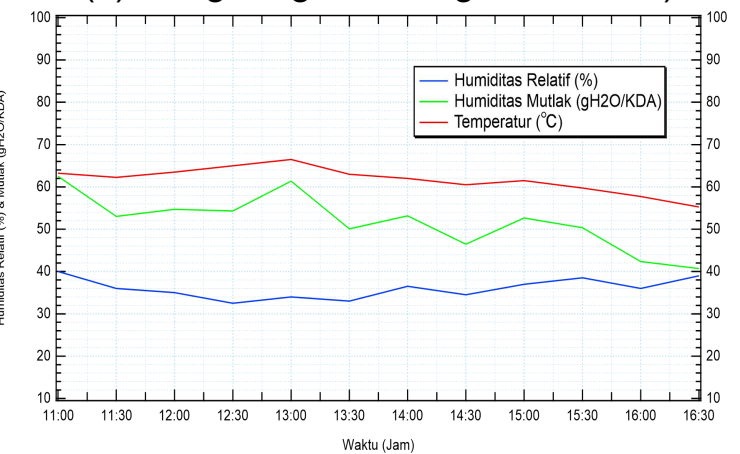

(d) Pengeringan 30 agustus 2018)

Gambar 5. Grafik Profil Laju Pengeringan Terhadap Kondisi Pengeringan Pada Percobaan Siang Hari

Tabel 2. Data hasil rata-rata pengujian pada konveksi paksa dan alami

\begin{tabular}{|c|c|c|c|c|c|c|c|}
\hline Pengujian & $\begin{array}{c}\mathrm{V} \\
(\mathrm{m} / \mathrm{s})\end{array}$ & $\begin{array}{c}\text { T1 } \\
\left({ }^{\circ} \mathrm{C}\right) \\
\end{array}$ & $\begin{array}{c}\text { T2 } \\
\left({ }^{\circ} \mathrm{C}\right)\end{array}$ & $\begin{array}{r}3\left({ }^{\circ} \mathrm{C}\right) \\
\end{array}$ & $\begin{array}{c}\mathrm{T} 4 \\
\left({ }^{\circ} \mathrm{C}\right)\end{array}$ & $\begin{array}{c}\mathrm{M} \\
\text { (gram) }\end{array}$ & $\begin{array}{c}\mathrm{T} \\
\text { (jam) } \\
\end{array}$ \\
\hline 1 & - & $\begin{array}{c}146,1 \\
2\end{array}$ & $\begin{array}{c}125,8 \\
1\end{array}$ & 57,23 & 33,50 & 213 & 7,5 \\
\hline 2 & - & 145 & $\begin{array}{c}130,6 \\
4\end{array}$ & 67,57 & 33,14 & 212 & 6,5 \\
\hline 1 & $3 \mathrm{~m} / \mathrm{s}$ & $\begin{array}{c}163,8 \\
5\end{array}$ & $\begin{array}{c}145,5 \\
0\end{array}$ & 63,03 & 33,64 & 209 & 6,5 \\
\hline 2 & $3 \mathrm{~m} / \mathrm{s}$ & $\begin{array}{c}141,1 \\
5\end{array}$ & $\begin{array}{c}122,7 \\
6\end{array}$ & 53,80 & 33,69 & 211 & 6 \\
\hline 1 & $3,5 \mathrm{~m} / \mathrm{s}$ & $\begin{array}{c}136,0 \\
6\end{array}$ & $\begin{array}{c}119,6 \\
0\end{array}$ & 54,25 & 32,06 & 211 & 7 \\
\hline 2 & $3,5 \mathrm{~m} / \mathrm{s}$ & $\begin{array}{c}154,3 \\
3\end{array}$ & $\begin{array}{c}130,8 \\
3\end{array}$ & 60,22 & 34,08 & 213 & 5,5 \\
\hline 1 & $4 \mathrm{~m} / \mathrm{s}$ & $\begin{array}{c}170,2 \\
5\end{array}$ & $\begin{array}{c}152,1 \\
6\end{array}$ & 61,68 & 34,58 & 212 & 6,5 \\
\hline 2 & $4 \mathrm{~m} / \mathrm{s}$ & $\begin{array}{c}161.4 \\
1\end{array}$ & $\begin{array}{c}143.1 \\
7\end{array}$ & 61.17 & 34.08 & 211 & 5,5 \\
\hline
\end{tabular}

Keterangan :

$\mathrm{V}$ = Kecepatan udara

T1 = Temperatur di kolektor

T2 = Temperatur di manifold

T3 = Temperatur di ruang pengering

T4 = Temperatur lingkungan

$\mathrm{M}=$ Massa asam gelugur setelah pengujian

$\mathrm{T}=$ Waktu pengering
Dari hasil pengukuran humiditas didalam ruang pengering diperoleh bahwa pada pukul 11.00 WIB proses pengeringan asam gelugur dapat menghilangkan kadar air yang terkandung pada asam gelugur dengan paling cepat yaitu mencapai 95,41\%.Naik turunnya grafik yang ditampilkan pada 
Gambar 4 dan 5 diakibatkan karena terjadinya dua fasa pada saat proses pengeringan asam gelugur didalam ruang pengeringan yaitu perpindahan panas dan perpindahan massa, kedua fasa ini tidak bisa berjalan sekaligus apabila perpindahan massa terjadi maka perpindahan panas tidak terjadi begitu sebaliknya panas yang terjadi pada ruang pengering sangat bepengaruh pada pelepasan uap air yang terdapat pada asam gelugur keudara, apabila semakin tinggi panas yang didapatkan pada ruang pengering maka semakin cepat untuk menghilangkan uap air keudara yang terdapat pada asam gelugur, begitu juga dengan sebaliknya. Untuk mendapatkan gambaran kondisi pengeringan maka datadata temperatur dan humiditas pada Gambar 4 dan Gambar 5 digunakan persamaan 1-3.

\section{Kinetika Pengeringan}

Dari data pemodelan kurva pengeringan pada Gambar 6, penurunan kadar air yang diperoleh selama percobaan pengeringan dikonversikan dalam bentuk hubungan rasio kadar air (MR) terhadap waktu pengeringan. Asumsi utama yang digunakan adalah temperatur dan kadar air didalam asam gelugur. Oleh sebab itu laju penurunan kadar air didalam buah asam gelugur adalah kasus 1 dimensi dinyatakan dalam bilangan kadar air tanpa dimensi (Moisture Ratio, MR) yang dapat dirumuskan pada Tabel 1. Profil laju pengeringan hasil percobaan dapat dilihat pada Gambar 6. Dari profil tersebut, diperoleh bahwa pada MR secara terus menerus berkurang sejalan dengan waktu pengeringan dan tidak terlihat adanya periode laju pengeringan konstan.

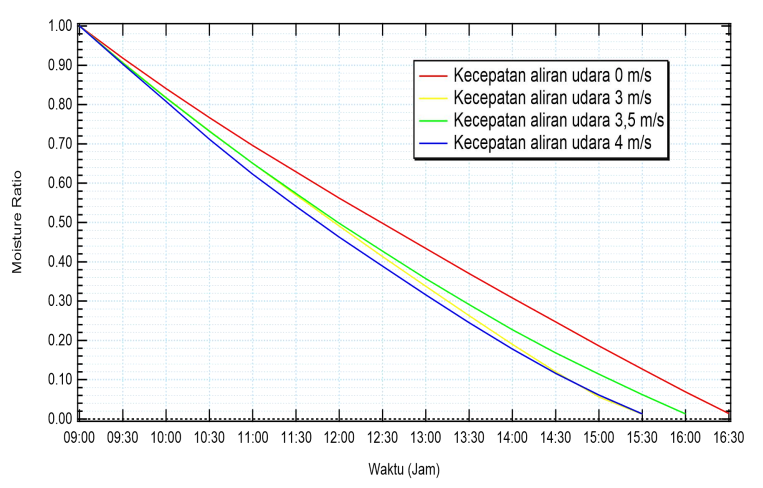

(a)

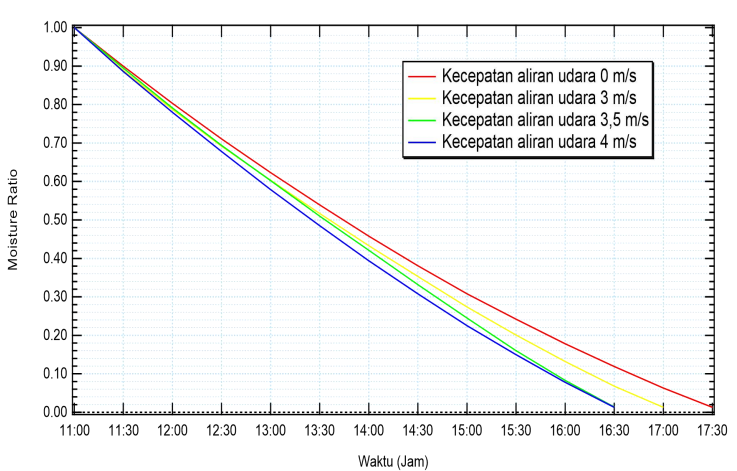

(b)

Gambar 6. Moisture ratio terhadap waktu pengeringan (a) Pengujian pada pagi hari (b) Pengujian pada siang hari

Model matematis untuk pencocokan kurva adalah Analisa regresi linier dan non linier diselesaikan menggunakan bantuan program Excell. Kriteria utama yang digunakan untuk memilih model terbaik adalah dengan menetapkan nilai tertinggi dari koefisien determinasi $\left(\mathrm{R}^{2}\right)$ serta nilai terendah dari akar kesalahan rata-rata kuadrat (RMSE) dan kesalahan bias rata-rata (MBE). Secara keseluruhan model wang \& singh dapat diasumsikan untuk mewakili perilaku pengeringan asam gelugur dengan persamaan

$M R=1+a t+b t^{2}$.

\section{KESIMPULAN}

Berdasarkan hasil pengeringan terhadap 2000 gram asam gelugur (Garcinia atroviridis) menggunakan pengering surya tipe kolektor tabung vakum baik dengan metode konveksi paksa maupun alami dapat disimpulkan beberapa hal, diantaranya pengeringan konveksi paksa memberikan laju pengeringan lebih cepat dibandingkan konveksi alamiah. Lama pengeringan juga dipengaruhi intensitas radiasi matahari dan kecepatan aliran udara pada ruang pengering Selam pengeringan berlangsung proses perpindahan massa dan panas berlangsung secara simultan. Hasil pencocokan kurva diperoleh bahwa model Wang \& Singh dengan persamaan: $\mathrm{MR}=1-0,0034 \mathrm{t}+$ $0,000002 \mathrm{t}^{2}$, dimana persamaan ini memiliki nilai RMSE dan MBE terendah yakni RMSE = 0,0040-0,0074, dan MBE =0,0002-0,0006. 


\section{DAFTAR PUSTAKA}

Adawiyah, Robiatul. (2014). Pengolahan dan Pengawetan Ikan. Jakarta: Sinar Grafika Offset Amran, Adel.A., Zakaria, Zaiton., Othman, Faizah dan Morat, Paden. (2010). Effect Of Gracinia Atroviridis on Oxidative Stress and Athetosclerotic Changes in Experimental Guniea Pigs.

American Journal Of Pharmacology and Toxicology \% (2): 65-70.

Arun Mujumdar and Chung Lim Law (2009), Drying Technology : Trends and Applications in Postharvest Processing Food and Bioprocess Technology.3,843852

Clement A. D., Assidjo N. E., Kouame P.,Yao K.B., ( 2009), Mathematical Modelling of Sun Drying Kinetics of Thin Layer Cocoa (Theobroma Cacao) Beans, Journal of Applied Sciences Research, 5 (9): 1110 1116.

Dasin DY, NY Godi,OC Kingsley ( 2015), Experimental Investigations of the Performance of Passive Solar Dryer Tested in Yola-Nigeria, International Journal of Energy Engineering,5 (1): 9-15.

Djoko A.W., Suryono Tatyantoro A. dan Tugino. (2009), Pemberdayaan Energi Matahari Sebagai Energi Listrik Lampu Pengatur lalu Lintas, Jurnal, Fakultas teknik Universitas Negeri Semarang, Semarang.

Henderson S.M and R.L Perry.(2009), Agricultural Process Engineering.AVI Publishing J. appl Sci. Res., 5(9): 1110-1116,

Kavak, A.E., (2010), Drying of Mint Leaves in a Solar Dryer and under Open Sun: Modelling,
Performance analyeses, energy conversion and management 51:2407-2418.

Rajagopal.T, S.Sivakumar. R. Manivel,

( 2014), Development of Solar Dryer Incorporated With Evacuated Tube Collector, International Journal of Innovative Research in Science, Enginnering and Technology, Vol 3, Issue3.

J. appl Sci. Res., 5(9): 1110-1116,

Sabiha MA, R.Saidur, Saad Mekhilef, Omid Mahian (2015), Progress and latest development of Evacuated TubeSolarCollectors. Renewable and Sustainable Energy Reviews, Elsevier.

Sundari Umayal A.R., Neelamegam P., Subramanian C.V., (2013), Performance of Evacuated Tube Collector Solar Dryer with and without Heat Sources, Iranica Journal of Energy \& Environment 4 (4): 336-342.

Suprayetno Dede, dkk. (2017), Pengaruh Variasi Laju Alir Udara Terhadap Kinerja Pengering Surya Tipe Kolektor Tabung Vakum. [skripsi]. Medan. Institut Teknologi Medan.

Ubale, AB, D.Pangavhane, A. Auti (2017), Performance analysis of Forced Vonvection Evacuated Tube Solar CollectorUsed for Grape Dryer.

Umayal Sundari AR, P.Neelamegam, CV Subramanian, Drying of Muscat Grapes in a Solar Drier with Evacuated Tube Collector, International Journal of Engineering, Vol 27, No.5.

Verdier N.A., Clement D. A., Ernest K.K. Emmanuel N.A., George N.A., Benjamin K. Y., (2015), Modelling of Thin Layer Drying Kinetics of Cocoa Beans in A Microwave Oven and Sun, Journal of Faculty of Food Engineering, Vol. XIV, Issue 2 - 2015, page $127-137$. 